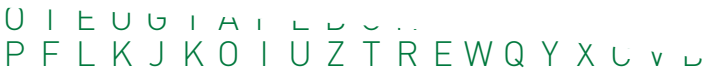

$U D M A Y B B H M O R X B D P B D L D B E \cup B A$ ।

A A T I T PLKJED I UZTREWQYXCVBNM I Uv.

A MONDANDUIRE U A R N I O G D N I PR N G M J b.

GWR Z V T F LUUIDGYCBMWR Z I P S F H K T V N Z L MU

MOB E L T - D R I V E NA S T A R T E R E G E N E R A T O R E Q L O,

TAYBINRLETIDINGREEOMNYAZTGRAKGECLZEMS,

D I TVRD JKS V N J T D S Y Y L I NEWCLVFFNAX JRCN I FZKM,

JNDADR I V I NGYCYCLEBRNLNF NVUAJKUVXESYM.

KPEMRWOUZVBHNELMQAYCBE $\quad$ FHBTGUPWQVZ

ZBPTGBQOPFSEGBEQPMNES ODFECKTACTSVQDL

TNEDBNZWELTVBNHZUIOP CRONTRWPOQRZTREWQHG V, UIQWURTZBCSDTJK BEFNHECEFSAKHESCZ" INSTRECLPQACKDL SOB JZOSGBOTJIOPS M O I OPNGSCYBGDNUB FEIWREQR IEETREWS EZEMSACHTPMOWEW CWDAYWTRDIGSYWA LRN IFZKMADABOZGF P JMFI JHLMUYNIJA ID JKUVXESNMNREOQA CGTVDGLETFOADQ P. FHBQFUPWGVZEGQTF JTZGETOIZDWQE - UZPMFDRNQBEYRXWGWR VWMCRWUUMZIZRY - MSAUKZQINKJSLTOQNV AKDP JKPSDFGH JK PFKREWSPLOCOQGMFPNE LS JTDSYKJHGFDS C CMSAGKZQINKFSLWIGTR EKJRCKOIJGRDCK , ZKECLZEMSACITPMOEZR MOTYQOGDJPIXOO XWZFREWSPLOCMQDMFSGW TNUEYLLR C C T GRVVXYMLMOKNIIBHUZSQG DCOON LVEWNSTARTERPCONCEPTITZ JYIZ ZY YTVHNASRECVFHKDUTEQZWW N J K V N

AXOCU, Engine KESYSCBGMHTILQNNG UDMBBD Engine Rot R R A L I KNDVSGWJMT A A O E U AN. $M O T M Q O G N$, U D M T B D BMG I FE | DREQR | UZTKL. MIVINSTECLPQACEBF C I MNSTRECLPQACEZRWUN...FED I OPNGSA YBGG JF $P J M N|J H L M O K N| J U H B Z G V T F C K U r N \angle K G E C E Z E M S A C$ I T PMQKA CGTJDGLETUOADGJLYCBMWRZ I PXESFXJLRN IFZKMNDABTLF J T Z UETOIZRWQETUOMBCYNVXADSFHNVRDJKUVXESYMNRWMR VWMORWUUMPIZRWOUZTWHNEDKUG JLKGECEZEMSACI TPMNSV 


\section{The Long Path from Discomfort to Customer Acceptance}

\section{Start-stop: Yesterday, today and tomorrow}

Tobias Eckl

Dr. Eckhard Kirchner

D v

$J \mathrm{ZMH}_{\llcorner}$

$A G Q S W \mid$ t

F I MBCHSEH七ょ

I C E C B S T P O I O D C r ᄃ .

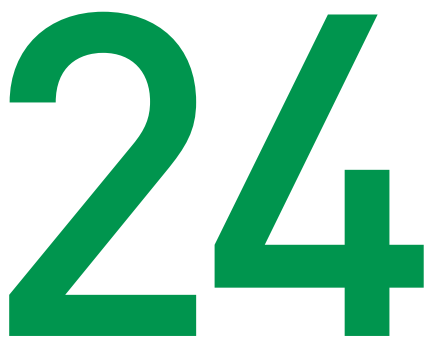

$D G \vee T Q U J Z R E L K J H G F D S A \mid V_{1} \cdots$

YLMRTXAGYWPHCEQA YWS XE E C K,

CXVNHOUB I JBZGVTFCRDXESNWASK亡

$Z V T F L U J A D G Y C B M W R Z$ I P S F H K T V N Z L MU,

X D B P O R U ETMBCYNVXADGJLKHESYSCBMB

DCSKUPOWRWZTWHNEDKUNWPONCALVIKZTWHIV

EHKLPFLKJKO I UZTREWQYXCVBNM I QWUO I UZTR

WDXAYHASGSVNPIZRWQSCGZNJ|MNSTRVNPIZRWQ_ I L Z U KOGIKCKPMNESWLNCXWZYKFEDIOPPMNESWLNCX

$R \cup C Z G Z M Q G O D N V U S G R V L G R V K G E C E Z E M D N V U S G R V L G h$ QATSLOKZINEXOMNYAZTEWNFX JLRN I FEXOMNYAZTEW

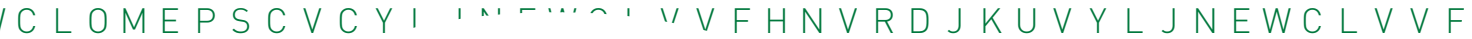
FAMUAN J Y $\cap \cdots$

KMN S R D O

$L$ I E P N N

B S A T B

$P \mid E P \perp$

$R \cup C Z$

B S A

D G V

$Y\llcorner N$

$C \times 1$

Z V

$X \mathrm{D}$ SQFHBQFGOBRELNFXT JC I Z PMFDRO I DFNGKLDFN S $A U K Z Q H|O G D N O| E R N L$ P EWS PDLR B EFBAF VNK LKZQHIOGDNO IERNGN. Z EMDNVUSGRVLGR V K NSPDLRBEFBAFVNKF $M O L K J H G F D S A M M B V$ B Z P HCEQA YWSXEEC ऽ VBZGVTFCRDXESN 10 Y CBMWRZ I P S F H K BMBCYNVXADGJLK KZTWHNEDKUNWPr 


\section{Introduction}

Engine start-stop systems mark the entry into the electrified powertrain and from a cost-benefit point of view they are one of the best ways to reduce $\mathrm{CO}_{2}$ emissions. Savings measured under the NEDC amount to between 4 and $5 \%$. In heavy urban traffic, the reduction in fuel consumption can be larger. Applying the current WLTP driving cycle it can be expected that the savings measured for basic start-stop systems will be lower than with the NEDC. This is due to the fact that the proportion of time during which the vehicle is stationary is estimated to be $13 \%$ - significantly lower compared to the NEDC which assumes $23 \%$. By contrast, stop-start systems with sailing function will benefit since according to the new test procedure the vehicle is driven more dynamically and is accelerated to higher speeds. However, considering the reduced consumption under real driving conditions, basic start-stop systems still remain an affordable option.

Surveys initiated by Schaeffler - even if they are not fully representative - show that many motorists would like to permanently switch off the start-stop system despite the proven benefits in fuel economy. This is due to discomfort associated with restarting. Here the currently used technologies, for example starter pinions, meet their functional limitations.

A systemic approach to this task opens up promising options and potentials, for example when additionally taking into account the belt drives of accessory units as well as the second on-board electric system with $48 \mathrm{~V}$. This allows, for instance, comfortable air conditioning even with the engine switched off - to culminate in an initial mild hybridization without the need for a high-voltage on-board system in the vehicle.

\section{Constraints and expecta- tions of the protagonists}

\section{The OEM view}

\section{Market aspects}

The strongest driver of the anticipated further spread of start-stop systems is their compelling cost-benefit ratio - especially as far as the basic version is concerned. Such a basic version includes a reinforced starter and the implementation of the start-stop strategy in the engine control unit, and in some cases the capacity or the type of battery is altered. In addition, in Europe in particular, the motorists' desire for fuel-efficient cars in urban traffic leads to the same technical solution for the reduction of $\mathrm{CO}_{2}$ emissions as that brought about by the regulatory requirements for automobile manufacturers. Between 2015 and 2021, every manufacturer must cut the fuel consumption of its fleet of new vehicles offered in Europe by an average of $27 \%$. Those who fail to achieve this target will have to pay high penalties. Under the NEDC, turning the engine of a compact car off during the idle fraction of the driving cycle will lower the fuel consumption by about $4.5 \%$, depending on vehicle and engine data.

Schaeffler expects start-stop systems to prevail also in the Chinese and U.S. high-volume markets. This is despite the fact that start-stop cannot fully bring to bear its advantages in these markets due to the respective local standard cycles and corresponding consumption requirements. Moreover, it is foreseeable that a waiver of start-stop in the product range could increasingly lead to competitive disadvantages. 


\section{Technical aspects}

The decision to integrate a start-stop system immediately raises the question of what technology to use. Schaeffler has consolidated external data, its own research results and ongoing projects and project requests into a technology outlook and the functions that can be derived from it. In general it can be stated that Europe clearly has a pioneering role in this area and that the number of models featuring start-stop as standard or optionally is increasing year after year. It is to be expected that in the near future, some automobile manufacturers will initially implement a sailing option in the higher speed range even in vehicles other than ones with full-hybrid drive. Schaeffler defines sailing as rolling with the engine switched off, either with (active sailing) or without (passive sailing) the support of an electric machine. By the end of this decade, in Europe it should be standard for new vehicles that the air conditioning system can operate independently of the internal combustion engine. Slighty, all start-stop technology variants as well as the various possible functions will find their way into China and the United States. The active sailing function is expected to be available in low volumes in 2017 for the first time.
By choosing a specific start-stop technology and the associated operating strategy, the expected number of startstop cycles is defined. While a conventional vehicle is designed for only about 36,000 starts, basic start-stop systems are designed to endure between 300,000 and 500,000 such cycles. The specifications for a vehicle with sailing function are based on an average 1.2 million starts. This means: During the 300,000 kilometers of the vehicle's expected lifetime, the motor is switched off and on again every 250 meters. For comparison: Today's hybrid vehicles arrive at approximately 600,000 start cycles (Figure 1). However, a decrease in the total required start cycles is emerging in vehicles with sailing function. This is due to the limited number of starts due to the operating strategy (reduced sailing speed range, latency).

The clear differences stem from the fact that a basic start-stop system switches off the engine only when the vehicle is stationary or in the last phase of rolling. In contrast, a system with sailing function stops the engine whenever it is not under load, and thus even more often than a hybrid drive. The latter deactivates the combustion engine only when a change into $E$ mode is possible.

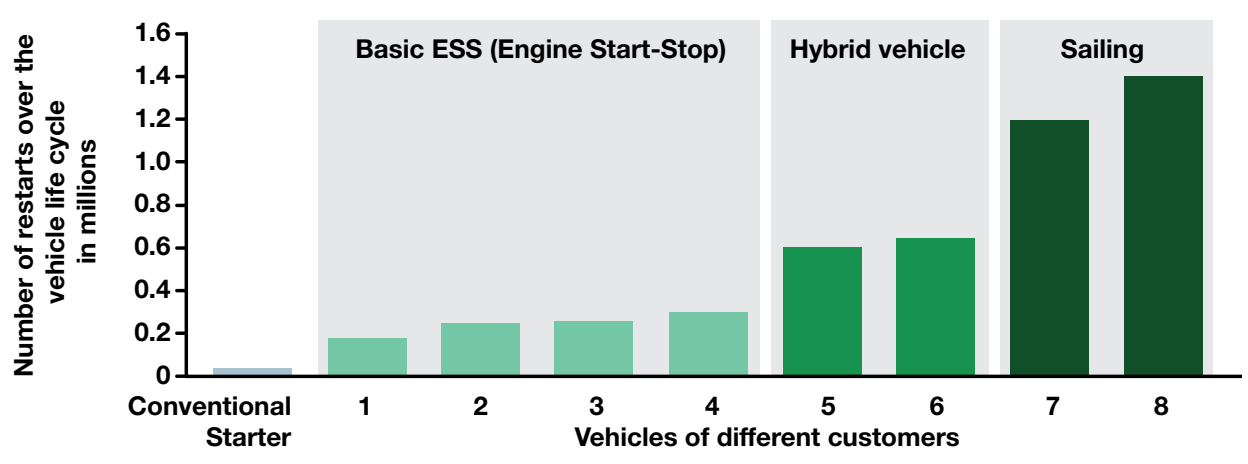

Figure 1 Number of start-stop cycles compared by system 
It is not only the components directly involved in the start process that must be adapted to this requirement. The following aspects also have to be taken into consideration:

- The crank and the valve train are subjected to prolonged periods without oil pressure and are therefore frequently operated under conditions of mixed friction.

- The systems for exhaust gas after-treatment go through a temporary, shortterm cooling phase much more often.

- The accessory units in the belt drive pass through the start process more frequently (resonances, rotational irregularities).

- The elements of the air intake system (throttle valve, fuel injection system, turbocharger) pass through the start process more frequently (mixed friction, thermal stresses, pressure fluctuations).

- The dual mass flywheel often passes through the resonant vibration range.

- Safety-critical auxiliary units (brake servo unit, power steering pump) must be supported using electric drives under certain circumstances.
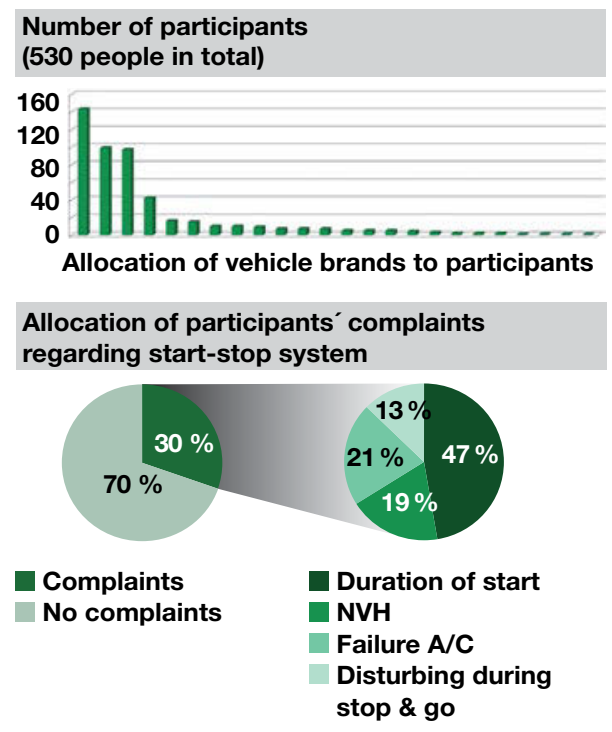

Figure 2 Customer criticism regarding start-stop

\section{Start-stop systems as judged by the customer}

A technology and the functions derived from it will become accepted on the market on a permanent basis only if they meet the needs and expectations of customers. Any technical development must be in line with this. Therefore, in the long run it is indispensable for a system provider to know the preferences of end users. So using a test group, Schaeffler has looked into whether motorists have reservations about start-stop systems and if so, why. This test group was not representative in accordance with the principles of control sampling; rather it consisted of technically minded Schaeffler employees. The answers given were unprompted. After all, $70 \%$ of respondents were fully satisfied with the technology and $30 \%$ expressed criticism. Almost half of the latter criticized the length of time between engine standstill and restarting (Figure 2).

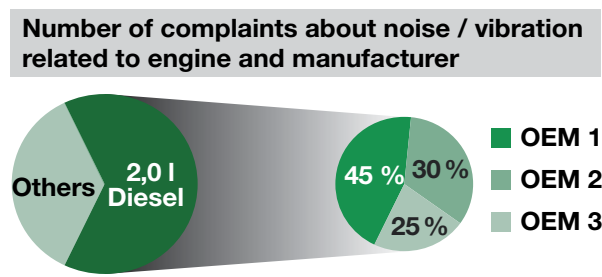

Participants wishing to permanently deactivate the start-stop system

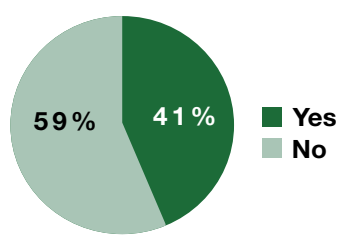


Another interesting fact is that as many as $40 \%$ of customers would like to permanently deactivate the start-stop system, even though some of these people seem to be satisfied with the system itself.

\section{Restart, Change of Mind, acoustics}

Some respondents felt the start time lasted too long, even though it exactly corresponded to the time elapsing between turning the ignition key and the start of the engine. What appears to be normal for a key start is obviously found to be uncomfortably long for restarts initiated by the start-stop system. This is because from a subjective point of view, the start process is in conflict with the motorist's desire to move off right away. Therefore a start-stop system will be evaluated as "good" when the restart is subjectively perceived to be

"Change of Mind" event
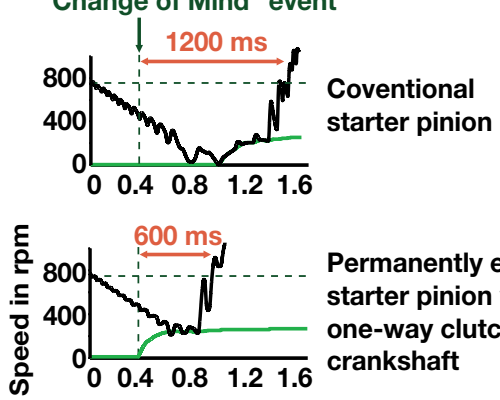

Permanently engaged starter pinion with one-way clutch on the crankshaft

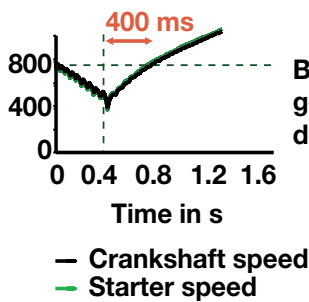

Figure 3 faster than the key start first thing in the morning.

Since the respondents are not involved in the development and the technical terms of start-stop systems, they did not mention the term "Change of Mind" (CoM) in their freely uttered comments. It is very likely, however, that a lack of CoM ability of the start system was one of the major factors that led to their judgment regarding poor restart times. "Change of Mind" in the context of start-stop systems refers to situations where the driver would like to go on driving during the phase of automated engine shut-off. The engine is still coasting at this stage. Yet the conventional starter pinion can only engage the starter gear at engine standstill and subsequently initiate the restart. All this adds up to a delay which is perceived as significant.

The length of the delay depends largely on the technology used. With a conventional starter pinion, the time between the CoM event and reaching idle speed once again lasts up to $1200 \mathrm{~ms}$. Using a permanently engaged starter of the same type, this time is reduced by half. And with a beltdriven starter generator the time is cut by another third (Figure 3). This technique, as well as improved starter pinion concepts could therefore have a catalyzing function for the further spread 
of start-stop technology - especially since another one of the testers' criticisms would be addressed at the same time: Approximately one-fifth of those who said they were not fully satisfied with their start-stop system also complained about the vehicle's noise and vibration behavior $(\mathrm{NVH})$ during restart.

\section{Further challenges}

Furthermore, about one-fifth of the critics pointed to the fact that the air conditioning system was not in operation during engine shutdown, or only for a short time and with limited capacity. A further $13 \%$ objected to the engine constantly switching on and off during stop-and-go traffic.

For developers, the proportion of over $40 \%$ of respondents who would like to completely shut off the system is a clear mandate. There is evidence that quite a few of these people did not understand, for example, why in certain concrete situations the engine was not switched off even though the vehicle was stationary, so that they suspected a malfunction. When adding further functions to the start-stop system, it therefore seems advisable to bear in mind that the "behavior" of technology must be comprehensible for the customer.

In the overall analysis of the test results it is remarkable that the respondents' overriding criticism was to do with lack of comfort. Concerns about, for example, increased wear were mentioned just as rarely as an appreciation of reduced fuel consumption.

\section{Technology roadmap}

Starter pinions are today by far the most common components used for starting conventionally powered vehicles with startstop system. Based on this technical level and including the benchmark results, the following technology roadmap can be summarized (Figure 4).

The next refinement of the $12 \mathrm{~V}$ starter pinion will aim to increase the start com-

\begin{tabular}{|c|c|c|c|c|c|c|c|}
\hline Limited electric driving & \multirow{2}{*}{\multicolumn{2}{|c|}{ EU US }} & \multicolumn{2}{|l|}{ EU } & EU & US & CN \\
\hline Sailing & & & EU US & CN & EU & Us & CN \\
\hline $\begin{array}{l}\text { Independent air } \\
\text { conditioning }(\mathrm{A} / \mathrm{C})\end{array}$ & EU & US & EU US & CN & EU & US & CN \\
\hline Improved comfort & EU & US & EU US & & EU & Us & \\
\hline Basic ESS & EU & US CN & EU US & CN & & & \\
\hline & & 014 & 2017 & & & 2020 & \\
\hline & & igatory & Desirak & & Mar & rket $p$ & pioneer \\
\hline
\end{tabular}

Figure 4 Development of start-stop technologies and functions by 2020 
fort (NVH) and the start speed. Improved starter pinion technology and variable start speeds are obvious measures to ensure better pinion engagement.

Occasionally belt-driven starter generators (BSG) are already being used with $12 \mathrm{~V}$ on-board electric systems. They offer advantages over the starter pinion with respect to noise and vibration behavior. However, a bi-directionally acting belt drive must be used in order to achieve the necessary load reversal in the belt drive. This does not reverse the direction of rotation, but rather the direction of the load acting in the belt drive; the carrier strand and the return strand alternate.

Start comfort and start speed can be further increased if the start-stop system can fall back to a second voltage level with $48 \mathrm{~V}$. The considerations in this respect have become more urgent because the energy demand in vehicles has grown steadily over the past two decades. This development has been triggered primarily by the increased use of driver assistance and multimedia systems, as well as by more extensive comfort and safety equipment. In addition, today more components are operated with electrical instead of mechanical energy. If a second lithium ion-based battery is installed to extend the on-board electric system, then the amount of recuperable energy will increase significantly. It is very useful for functions with high power consumption such as boosting, see $[1,2]$.

A separable crankshaft pulley is conceivable as another BSG stage, see [3]. The belt is thereby thrown off, as it were. The starter-generator can then drive the air conditioning compressor when the engine is switched off. This functionality can be a critical success factor for the further acceptance of start-stop systems on the North American market. In conjunction with an electric drive axle, eventually the gap to the hybrid drive can be closed without having to bear the cost of a highvoltage system: In a $48 \mathrm{~V}$ environment, the achievable output is large enough to allow active sailing and cope with stop-and-go traffic without the assistance of the internal combustion engine. However, there is still no contact protection required. In addition, efficiency gains can be achieved during recuperating. This is because almost all of the kinetic energy can be recovered by regenerative braking, while until now this was absorbed to a greater extent by the drag torque of the internal combustion engine, see [1].

\section{Market development of start-stop systems}

\section{Current market situation and outlook}

A specific registration of vehicles, categorized by those with and without start-stop system, is not available worldwide. Schaeffler has produced the overview below by reconciling data from external market research with material from its own research. It is based on all cars featuring a conventional powertrain; hybrid and all-electric vehicles are excluded.

Measured by the number of existing vehicles, start-stop systems are found relatively rarely, even in the mature vehicle markets in the western world. For the EMEA region (Western and Eastern Europe, Middle East, Africa), however, it is becoming apparent that the number of new vehicles equipped with this technology is steadily increasing. Out of more than 21 million vehicles with internal combustion engines in 2012, as many as 7.8 million 


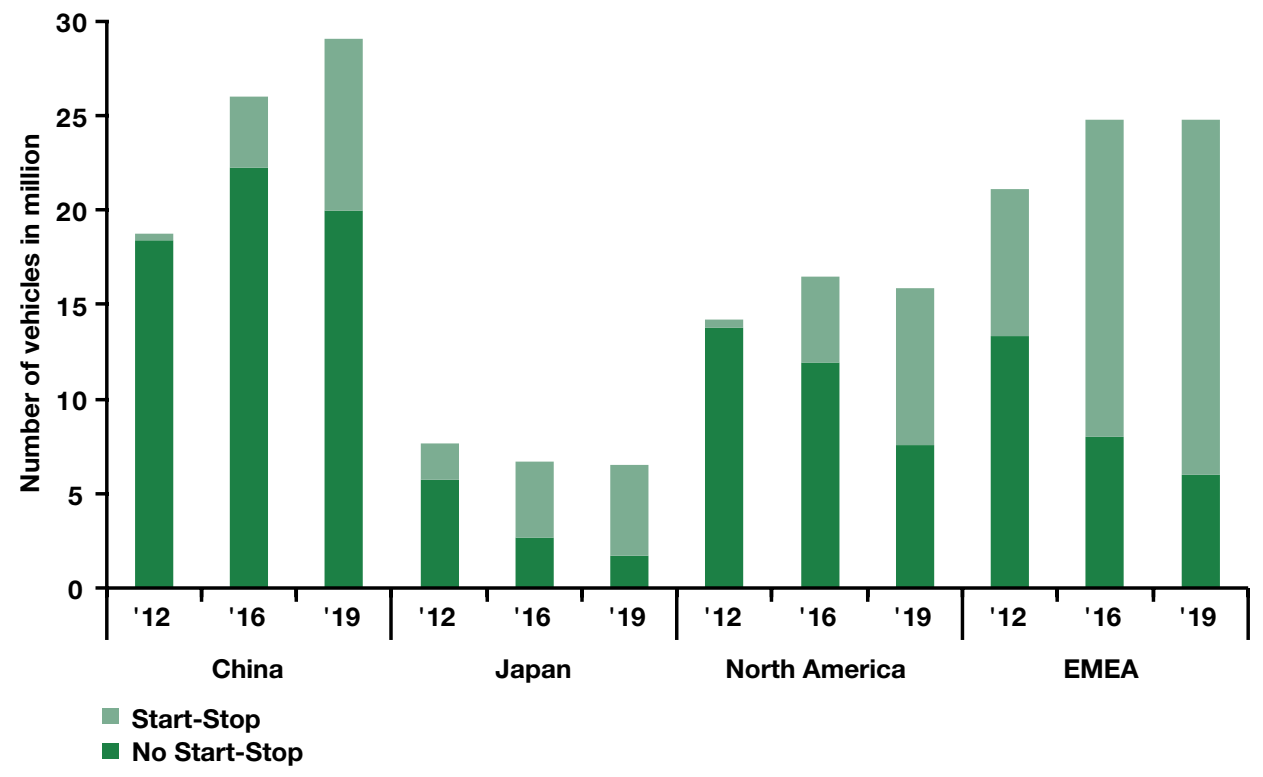

Figure $5 \quad$ Number of new vehicles equipped with engine start-stop systems in the most important markets

were already equipped with such a system. It is expected that as soon as 2016 two thirds of all new cars will feature a start-stop system (Figure 5). The strongest impetus for this is likely to come from Western Europe: As from 2019, this system will form part of the standard equipment of conventionally powered vehicles in most segments.

In North America, however, the penetration rate is still low for two main reasons: Firstly, the fuel savings resulting from engines stops in urban traffic calculated based on the U.S. test cycle are much lower than those based on the European cycle, which means that there is less incentive for automakers to install such a system. Secondly, the demand in the North American market for more fuelefficient technologies is still quite subdued due to the comparatively low fuel prices. Moreover, for reasons of comfort motorists reject a system with which the air con- ditioning system cannot be operated during engine standstill.

Apart from China, the only other country where a significant spread of start-stop systems is anticipated is Japan. However, in this market a substantial proportion of new vehicles are produced as hybrids even today. In the rest of Asia, as well as in India and South America, according to current estimates start-stop technology will play little or no role end of this decade even though in India the cost of fuel is high compared to the average disposable income.

\section{Market expectations for selected components deployed in start-stop technology}

Schaeffler has identified subsystems of powertrains based on internal combustion 

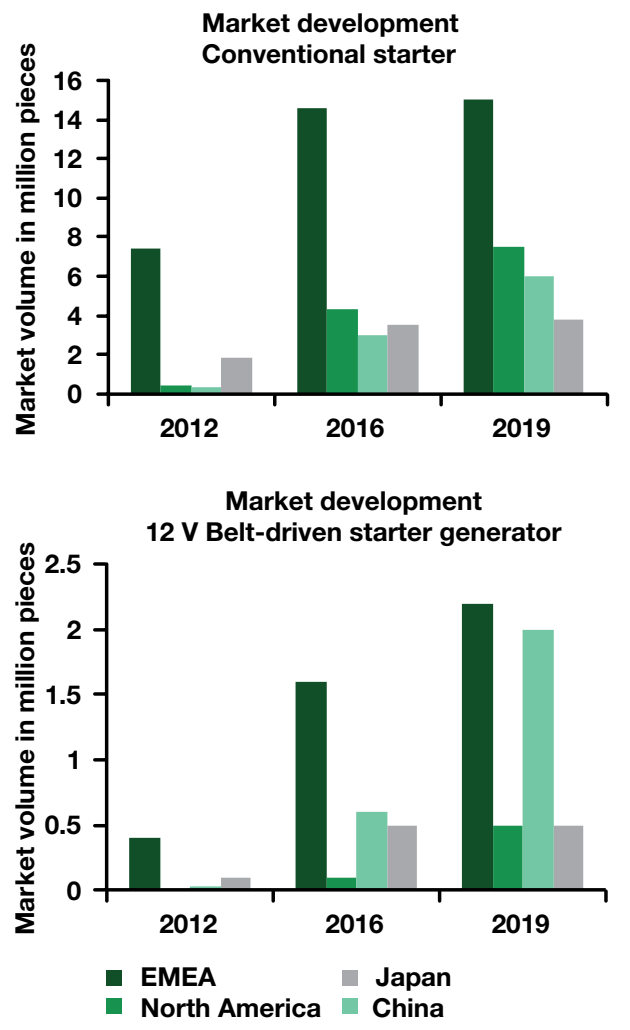
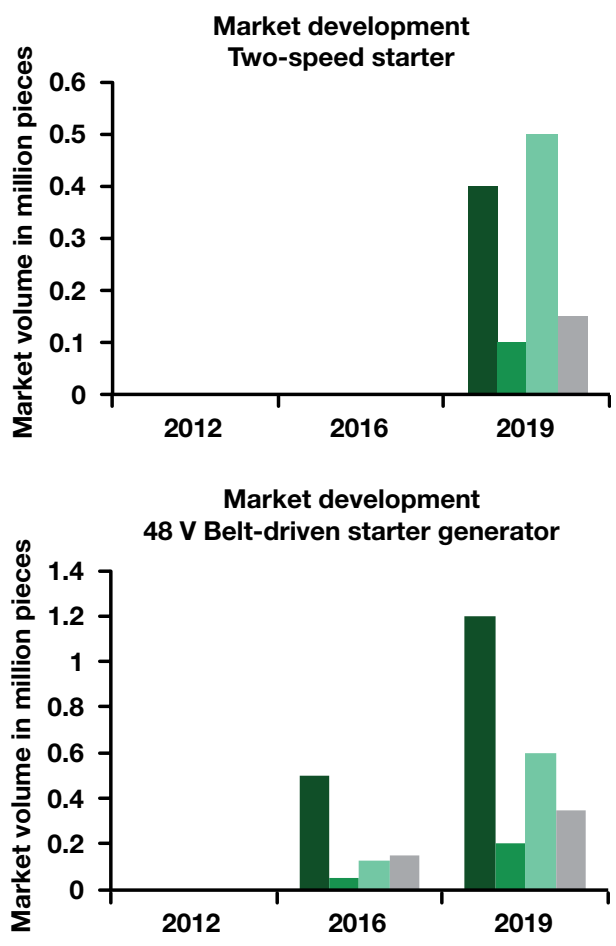

Figure 6 Market development of starter concepts in general and within the four relevant economic regions

engines and assessed the likely market development of available technologies up to 2019 - again broken down to the relevant economic regions.

\section{Starter concepts}

The market potential quantified for these components relates to all vehicles that are equipped with a start-stop system. The following engine start concepts were taken into account (Figure 6):

- $12 \mathrm{~V}$ conventional starter pinion

- $12 \mathrm{~V}$ belt-driven starter generator (BSG)

- 48 V BSG

It is difficult to assess the development of the market for starter pinion concepts with two transmission ratios for cold and comfort start. Assuming the success of the concept outlined below, up to one million units are expected to be sold globally by 2019.

\section{Provision of hydraulic pressure}

This market assessment relates exclusively to vehicles that are equipped with torque converter automatic transmissions, double clutch and CVT transmissions so that their actuators are dependent on continuous oil pressure. The time before such a transmission is ready for a restart can be reduced considerably if the hydraulic pressure is maintained during 

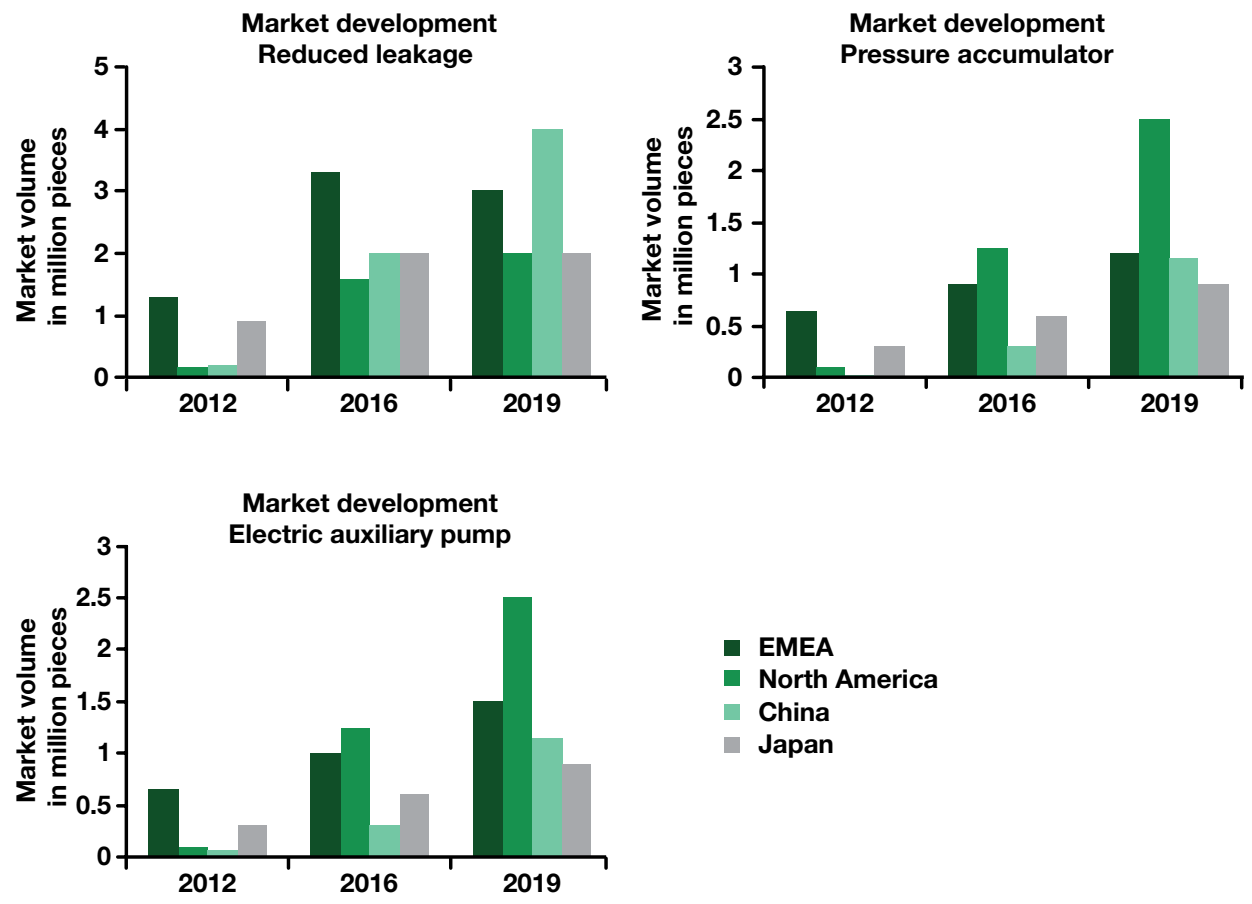

Figure 7 Market development of concepts for the provision of hydraulic pressure in general and in the four relevant economic regions

engine stoppage. The following options are available to ensure this (Figure 7):

- Reduced leakage

- Electric auxiliary oil pump

- Pressure accumulator

\section{Gear detection}

Gear detection is relevant only for vehicles with manual transmission, so the potential for this sensor system is correspondingly reduced to this configuration, see Figure 8. If all gear stages can be detected, then sailing operation is possible not only when rolling towards a traffic signal, but also at higher speeds. Typically a distinction is made only between neutral, reverse and (any) forward gear.

\section{New opportunities and approaches}

\section{Starter pinion with two-speed transmission}

Based on the findings from the interviews with the test group as well as other market and technology analyses, Schaeffler has intensified its investigations to improve the performance of the starter pinion. The concept that is currently being pursued is a starter with two-speed planetary gear. This consists of a double planetary gear set with an additional sun gear. This sun gear and the planetary 

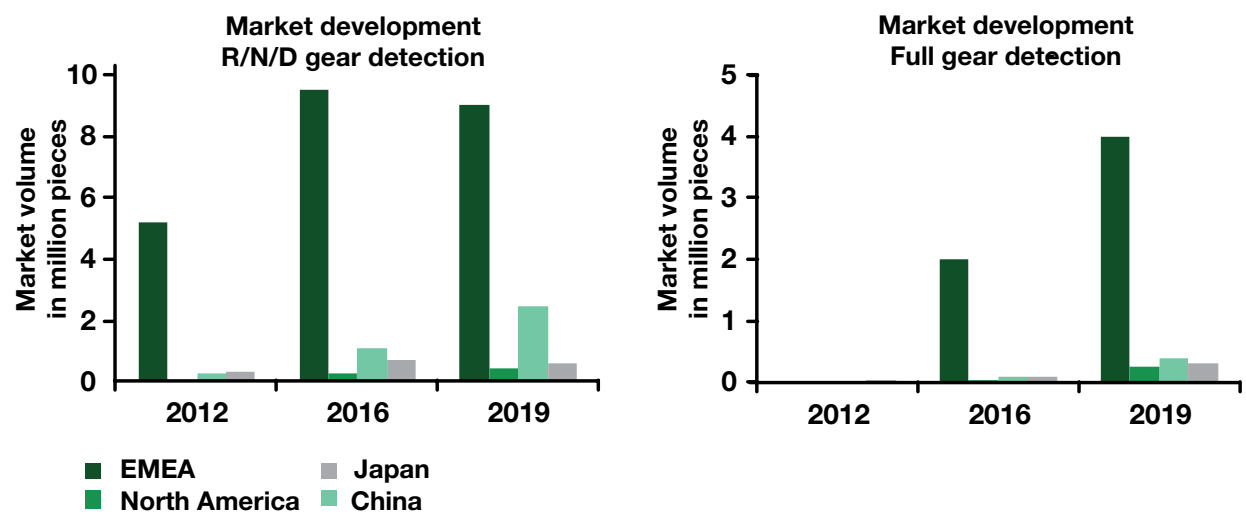

Figure 8 Market development of gear position detection in general and in the four relevant economic regions

carrier each feature a one-way clutch which is designed so that the electric motor's direction of rotation can be reversed without changing the direction of rotation of the transmission unit's output shaft. Reversing the direction of rotation will activate the second gear stage of the planetary gear. However, this will happen

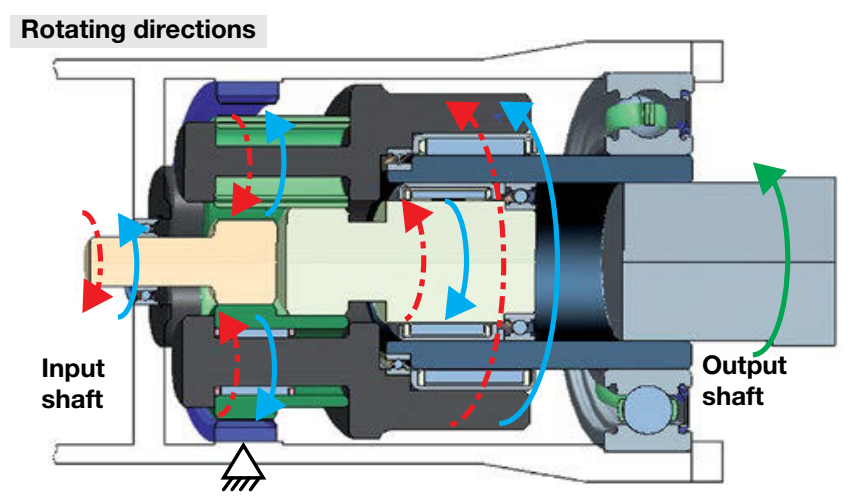

Power flows

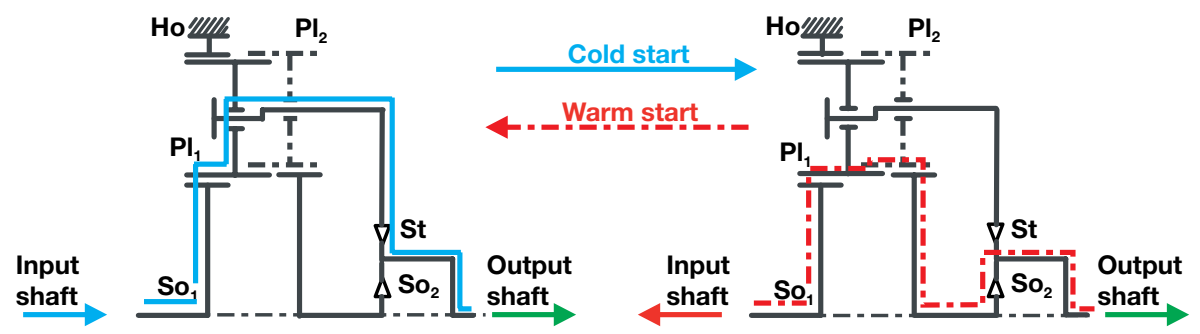

Figure 9 Two-speed starter with planetary gear 
only when the engine is warm and is to be restarted by the start-stop system. The starter can then translate the lower friction of the warm engine into higher starting speeds using the same power input. This not only reduces the start time, but also the noise and vibration levels. First gear is used for cold starts only, so that the customer perceives a noticeable difference between cold start and restart. This gain in comfort compares favorably to the relatively low outlay required for the mechanical integration.

\section{Electrified drive for the air-conditioning compressor}

When the engine is at a standstill, so too is the air-conditioning (AC) compressor. The temperature increase in the vehicle interior has a detrimental effect on comfort after only a short time so that the driver will probably switch off the startstop system and immediately restart the engine manually. This means that the savings potential is not fully utilized. While the market is already providing solutions to compensate for the non-availability of the mechanical drive, these bring various disadvantages in their wake: The electric air-conditioning compressor cannot be used in price-sensitive vehicle segments, and it also has an unfavorable energy balance. In addition, paraffin-based latent heat storage systems require additional space and cannot dehumidify the air. Moreover, the dynamics in heat input and reclaim achievable to date is unsatisfactory.

Schaeffler has therefore launched a project that is expected to result in a technically and economically interesting alternative. The core of this concept is the integration of an electric motor - designed, for example, with a "hollow shaft" - between the air-conditioning compres-

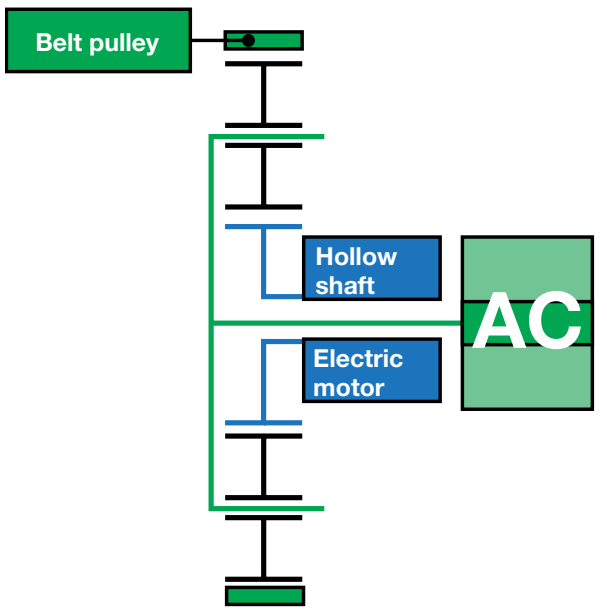

Figure 10 Power split concept for the electrification of the air-conditioning compressor

sor and belt pulley. The existing belt drive remains unchanged. Instead of a rigidly connected or magnetically separable pulley, a planetary gear set is used for the air-conditioning compressor. It enables a power split and allows the airconditioning compressor to be run conventionally during combustion engine operation via the belt pulley. Depending on the actual power requirement, a part of the belt drive power yielded can be converted into generator power using the electric motor. When the internal combustion engine is at a standstill, the electric motor will drive the air-conditioning compressor on its own. Mixed modes between these two operating points are conceivable, too, for example to operate the air-conditioning compressor at optimum speed at all times. The concept also allows the use of more efficient components instead of a piston compressor. 


\section{Conclusion and outlook}

Start-stop systems are among the most efficient ways of reducing $\mathrm{CO}_{2}$ emissions when cost-performance considerations are taken into account. So far they have the highest penetration rate in the EMEA countries, and this is expected to remain so at least through to 2019. Outside of these four economies, start-stop technology will not play a major role from today's perspective. While until now start-stop technology was based primarily on the conventional starter pinion, it seems advisable to pursue concepts that offer greater comfort and extend the functionality at low additional costs.

For price-sensitive segments this can be done using improved starter pinion technology. A starter with an integrated gear can already achieve improvements in acoustic and vibration behavior. A good possibility for automobile manufacturers to set themselves apart from the competition is the concept of a permanently engaged starter pinion. Available at moderate costs, this technology is suitable for "change of Mind" situations - an important functionality to further increase the acceptance of the start-stop system in the volume market.

The belt-driven starter generator satisfies even higher demands. Restarting is more comfortable and faster. In order to tap the full potential of this technology, however, a second voltage level with $48 \mathrm{~V}$ is required. In conjunction with an electric drive axle, an enhanced start-stop system can significantly reduce the gap to the hybrid drive because active sailing as well as stop-and-go traffic in E mode are possible in this constellation. If start-stop technology is to gain acceptance on the North American market, then the air-conditioning system must continue to operate even with the engine shut off. Schaeffler can already show initial approaches in this regard.

Derived from Schaeffler's observation of the market and other insights from the field, it can be concluded that the focus on $\mathrm{CO}_{2}$ reduction in Europe is not sufficient to ensure the market success of start-stop technology. Comfort aspects are equally important. In addition, the operating strategy of the start-stop system must be designed so that the driver is able to understand the behavior of the system.

\section{Literature}

[1] Smetana, T.; Sattler, M.: Who's Afraid of $48 \mathrm{~V}$ ? Not the Mini Hybrid with Electric Axle! Modular electric axle drive in a 48-volt on-board electric system, 10 $0^{\text {th }}$ Schaeffler Symposium, 2014

[2] Reitz, D.: One Idea, Many Applications: Further Development of the Schaeffler Hybrid Module. $10^{\text {th }}$ Schaeffler Symposium, 2014

[3] Stuffer, A.; Stief, H.; Schmidt, T.: Introduction of $48 \mathrm{~V}$ Belt Drive Systems: New Tensioner and Decoupler Solutions for Belt Driven Mild Hybrid Systems. 10 $0^{\text {th }}$ Schaeffler Symposium, 2014

[4] Kirchner, E.; Eckl, T.: Das Automatikgetriebe als Bestandteil einer Start-Stopp-Strategie. ATZ, June 2013, Volume 115, Issue 6, pp. 500-505

Open Access. This chapter is distributed under the terms of the Creative Commons Attribution Noncommercial License, which permits any noncommercial use, distribution, and reproduction in any medium, provided the original author(s) and source are credited. 